U. S. Department of Commerce

REFERENCE National Bureau of Standards

CHECKING PACKAGED AEROSOL PRODUCTS, HIGH VISCOSITY

\author{
A Supplement to
}

National Bureau of Standards Handbook 67

Checking Prepackaged Commodities

Issued June 11, 1965

$Q C$
.451
No.67
Suppl.
$6-11-6$ 



\section{CHECKING PACKAGED AEROSOL PRODUCTS, HIGH VISCOSITY}

This procedure covers the checking of high viscosity type aerosol packaged products (see attached list for examples) and has been prepared as an addition to the package checking procedures presented in National Bureau of Standards Handbook 67.* Reference to other procedures are those contained in Handbook 67.

The step-by-step procedure set forth below has been developed as a parallel to Steps 1 through 5 on page 11 of Handbook 67 which are directed to conventional standard-pack packages.

\section{Standard-Pack Packages, Aerosol Products (High Viscosity)}

(High viscosity aerosol products should be at a temperature between $70^{\circ}$ to $80^{\circ} \mathrm{F}$. when checked. The fumes and the product released when emptying the containers may be toxic and/or flammable. The exhausting procedure should be conducted in a wellventilated area or outdoors. No smoking should be permitted in the test area. The containers should not be punctured or subjected to temperatures in excess of $110^{\circ} \mathrm{F}$. )

Step 1. - -Select a sample of 10 or more identical packages (identical as to labeled weight, brand, and commodity). Remove any overcaps not required for dispensing the product.

Step 2.--Check the gross weight of each package to determine the lightest and heaviest package in the sample. Record the gross weight of the lightest and heaviest package.

Step 3.--Following directions on the container, prepare the lightest package for the checking procedure. If shaking is specified, the shaking should be done according to the directions on the container. If no specific directions as to how the can should be shaken are given, shake the container with a brisk wrist-twisting motion for one minute at the approximate rate of two complete cycles per second. If the sample contains a ball agitator, this shaking procedure should continue for one minute after the ball has shaken loose.

\footnotetext{
*Copies of Handbook 67 are available from the Superintendent of Documents, U. S. Government Printing Office, Washington, D. C. 20402, at 35 cents per copy. (Remittance must accompany order. Postage stamps not acceptable.)
} 
Step 4. --Exhaust the lightest container by holding the valveactuator depressed until the visual spray pattern is interrupted. During this exhausting procedure the container should be held in the proper position (generally upright) as specified in the directions on the package. (A lightweight, portable test stand equipped with an adjustable valveactuator depressor used in conjunction with a receiving vessel may be used for this operation. See Figure 1.)

As soon as the visual spray pattern is interruped, release the actuator. Allow the container to warm up to $70^{\circ}$ to $80^{\circ} \mathrm{F}$. before concluding the evacuation. Agitate the container with a swirling motion for 30 seconds. Hold the container at approximately a $45^{\circ}$ angle, with the valve-actuator depressed, and rotate the container to maintain the visual spray as long as possible. (This will ensure contact of the dip tube with any remaining liquid in the container.) Continue this procedure until no additional liquid or gas is expelled.

Step 5.--Rinse with a suitable solvent and dry the exterior of the container. (If the valve-actuator is removable, remove for cleaning and drying, and then replace.)

Step 6.--Weigh the empty container to determine the wet tare. (The wet tare is defined as the weight of the container plus any product that is not expelled during the exhausting procedure.)

Step 7.--Determine the test allowance by reference to the following table. (The test allowance is an allowance for the difference in the amount of product delivered through normal consumer usage and the amount of the product delivered through the procedure outlined in Step 4.)

Labeled Weight of Package

Test Allowance

\begin{tabular}{cc}
\hline Fractional & Decimal \\
Zero & Zero \\
$1 / 16 \mathrm{oz}$ & $0.06 \mathrm{oz}$ \\
$2 / 16 \mathrm{oz}$ & $0.13 \mathrm{oz}$ \\
$3 / 16 \mathrm{oz}$ & $0.19 \mathrm{oz}$ \\
$4 / 16 \mathrm{oz}$ & $0.25 \mathrm{oz}$
\end{tabular}


Step 8. --Subtract the test allowance from the wet tare to obtain the corrected wet tare.

Step 9.--Subtract the corrected wet tare from the gross weight to obtain the adjusted net weight of the lightest package.

Step 10. --If the adjusted net weight of the lightest package at least equals the declared net weight, it may be reasonable to assume that the lot is satisfactory.

Step 11. - -If the adjusted net weight of the lightest package is less than the declared weight, it will be necessary to treat the 10 packages as a sample of the lot and proceed to weigh them individually to determine individual errors. For this procedure it will be essential to arrive at an average corrected wet tare weight to be added to the labeled net weight of the package to determine a "standard" gross weight with which the packages will be compared.

In order to arrive at a representative average corrected wet tare weight for the sample, Steps 3 through 8 must be repeated with the heaviest package to obtain its corrected wet tare weight. The average of the two corrected wet tare weights may then be accepted as the tare weight for the weighing of individual packages. In rounding off this average always round off to the lower figure (i. e., the average of $210 / 16 \mathrm{oz}$ and $211 / 16 \mathrm{oz}$ is $210 / 16 \mathrm{oz}$ ). (The inspector is cautioned that the tare of a single package is not considered acceptable as an average corrected wet tare, and also that no "permanent" or "reference" record of tares is acceptably reliable.)

Step 12.--With standard weights in an amount equal to the "standard" gross weight for the sample packages on one side of the scale (or as the "standard" gross weight in the "substitution" procedure if an equal-arm scale is not used), weigh the remaining packages of the sample and record the error of all sample packages. Exclude, by circling, any errors $( \pm$ ) that are unreasonably large and determine an average error for the sample (see Steps 1, 2, 3, 4, and 5 of 8.1., NBS Handbook 67). 


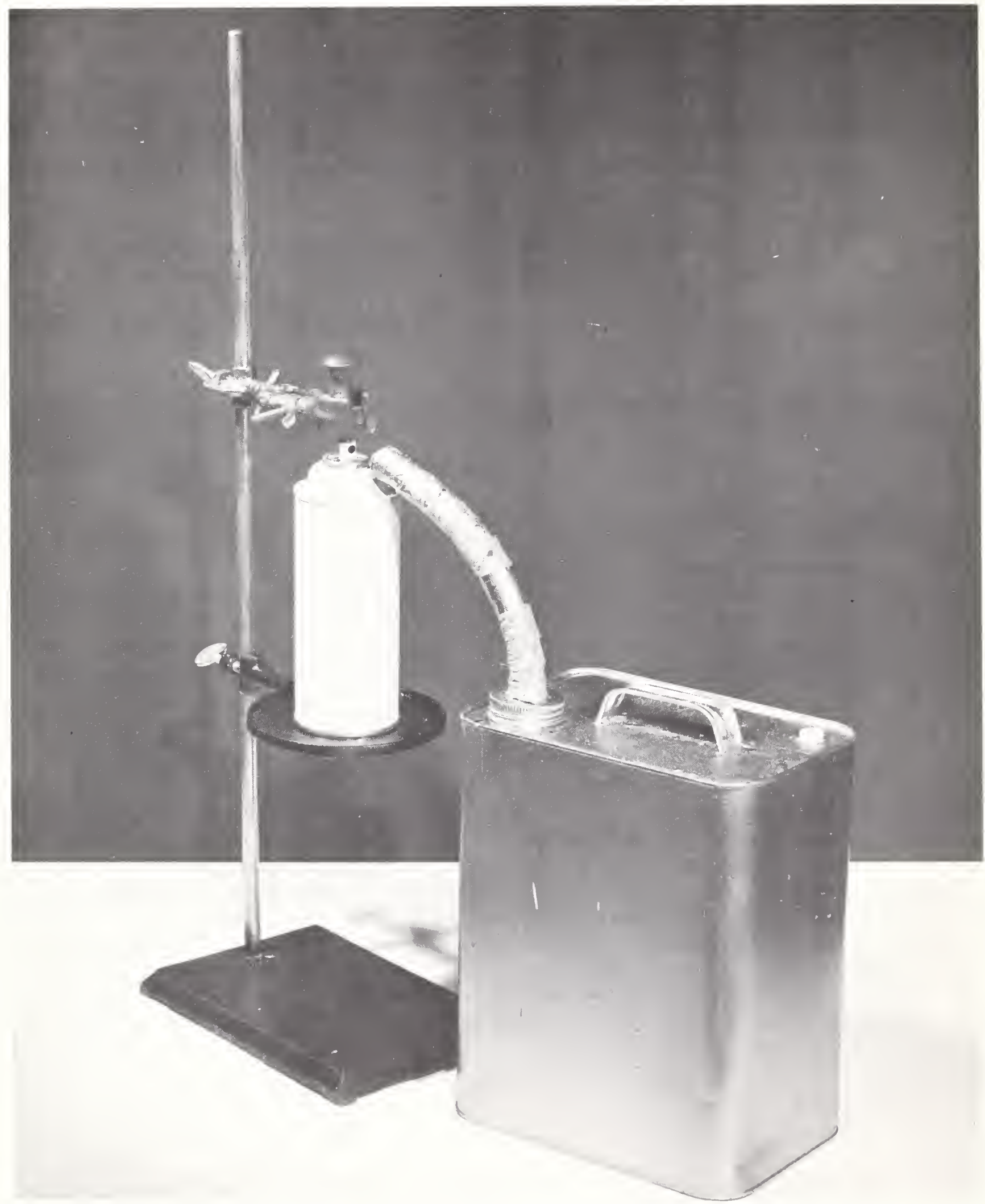

Fig. 1. A lightweight, portable test stand with an adjustable valveactuator depressor and a receiving vessel. (Component list, assembly, and operation described on the facing page.) 
The lightweight, portable test stand with the adjustable valveactuator depressor and receiving vessel may be assembled easily. The major components are available from any scientific supply company. The components and the approximate cost are as follows:

$\underline{\text { Item }}$

Support Stand

Support Plate

Utility Clamp

Gasoline Can

Carriage Bolt ( $1 / 2$ in.,

$2-3$ in. long) and Nut
Approximate Cost

$$
\begin{array}{r}
\$ 2.00 \\
2.25 \\
1.75 \\
1.00 \\
\quad .10 \\
\$ 7.10
\end{array}
$$

In the assembly of the stand, the carriage bolt is threaded into the nut and the nut is gripped tightly by the rubber covered jaws of the clamp. The clamp and support plate are then mounted on the rod of the support stand.

In the operation of the stand, the support plate is adjusted so that the orifice of the spray can is lined up with the intake of the receiving vessel. Be sure that the vent on the vessel is left open and clear. The height of the clamp is adjusted to the height of the container under test and the final valve-depressing adjustment made by turning down the carriage bolt until maximum flow of product is obtained. 
EXAMPLES OF HIGH-VISCOSITY AEROSOL PRODUCTS

\author{
Paints \\ Enamels \\ Lacquers \\ Acrylic Coatings \\ Varnishes \\ Undercoatings
}



1 